\title{
Sumak Kawsay: Una cosmovisión desde el sur con sentido de justicia bio-social
}

\author{
Sumak Kawsay: A Worldview from the South \\ with a Sense of Bio-Social Justice
}

\section{Sumak Kawsay: uma Cosmovisão desde o Sul com Sentido de Justiça biossocial}

\author{
Pascual G. García Macías
}

Fecha de recepción: 24 de julio de 2016

Fecha de aprobación: 27 de enero de 2017

Doi: http://dx.doi.org/10.12804/revistas.urosario.edu.co/anidip/a.5674

Para citar este artículo: García Macías, P.G. (2017). Sumak Kawsay: Una
cosmovisión des de el sur con sentido de justicia bio-social. Anuario
Iberoamericano de Derecho Internacional Penal - ANIDIP, 5, 138-156,
doi: http://dx.doi.org/10.12804/revistas.urosario.edu.co/anidip/a.5674

\section{Resumen}

El presente artículo pretende exponer la importancia de la economía solidaria, con el propósito de analizar la crisis actual (manifestada por factores como el cambio climático, el agotamiento y el desgaste de los recursos naturales, así como la persistencia de brechas socio-económicas) y contribuir a la cimentación de una propuesta de desarrollo económico con justicia biosocial, como una corriente reciente de pensamiento crítico. Comenzamos con el análisis de los orígenes epistemológicos del desarrollo dentro de los postulados de Marx y Engels. A continuación, exploramos brevemente la relación entre capital y naturaleza a través de algunas propuestas post-desarrollistas, varias de ellas devenidas de los movimientos sociales indigenistas. Finalmente, proponemos el Sumak Kawsay como una propuesta de desarrollo para el hombre común.

\footnotetext{
Profesor de tiempo completo en la Universidad Técnica Particular de Loja, en el Ecuador. Tiene un doctorado con mención internacional en Movilidad Humana por la Universitat de Valencia, realizó su maestría en el Máster Internacional en Miģraciones por la Universitat de Valencia, España, en colaboración con: Universite Catholique de Lille, Francia; University of Canterbury, Kent, Reino Unido; University of Applied Sciences of Western, Ginebra, Suiza; y Universidad Surcolombiana, Colombia. Dentro de sus publicaciones se encuentran "Incidencia del uso del internet en el desarrollo de la comunidad Andina" publicado en CISTI 2016. y "Los siete muros de la Vergüenza de Europa” publicado por la red internacional de migración y desarrollo. 2016. El autor ağradece a Karina Ponce Silva, estudiante de economía de la Universidad Técnica Particular de Loja (Ecuador) por su excelente contribución durante la investigación y edición del presente trabajo.
} 
Palabras Clave: Sumak Kawsay, desarrollo económico, justicia biosocial, buen vivir, decolonialidad.

\begin{abstract}
The present article aims to expose the importance of solidary economy for analyzing the current crisis (manifested by factors such as climate change, depletion and erosion of natural resources and the persistence of socio-economic gaps) and contributing to the strengthening of a proposal that combines economic development and bio-social justice, as a recent trend of critical thought. The article starts with the analysis of the epistemological origins of economic development within the postulates of Marx and Engels. Subsequently, the relationship between capital and nature through some post-developmental proposals, including those developed from the pro-indigenous social movements, is explored. Finally, the article proposes the Sumak Kawsay as a development model for the common man.
\end{abstract}

Keywords: Sumak Kawsay, económic development, biosocial justice, well-living, decolonize.

\title{
Resumo
}

O presente artigo pretende expor a importância da economia solidária com o propósito de analisar a crise atual (manifestada pelos fatores como a mudança climática, $o$ esgotamento e o desgaste dos recursos naturais, bem como também a persistência de brechas socioeconómicas) e contribuir à cimentação de uma proposta de desenvolvimento económico com justiça biossocial, como uma corrente recente de pensamento crítico. Começamos com a análise das origens epistemológicas do desenvolvimento dentro dos postulados de Marx e Engels. A continuação exploramos brevemente a relação entre capital e natureza através de algumas propostas pós-desenvolvimentista, várias delas resultantes dos movimentos sociais indigenistas. Finalmente, propomos o Sumak Kawsay como uma proposta de desenvolvimento para o homem comum.

Palavras-chave: Sumak Kawsay, Desenvolvimento Económico, Justiça Biossocial, Bom Viver, Decolonialidade.

\section{Introducción: ¿Qué es el desarrollo?}

Para poder entender lo qué es el desarrollo, debemos hacer un breve bosquejo histórico-crítico del concepto, ya que fue en Occidente donde se planteó un mandato ideológico rotundo del "desarrollo" como meta a la que debía lograr el resto del mundo, en la que el ideal era el modelo de estilo de vida norteamericano, conocido también como American Way of Life, Así quedó estipulado que el mundo desarrollado 
sólo existía con su opuesto; el subdesarrollo, lo que permite corroborar que la idea de desarrollo se gesta desde una percepción dominante, como lo fue en su momento la «modernidad» y después el «progreso», un progreso de origen colonial, opresor, que se sintetiza por una relación dominado-dominante (Fanon, 2012). Así las cosas, desde entonces, ${ }^{1}$ según las comunidades y sociedades en todo el planeta fueron y siguen siendo reordenadas para adaptarse al desarrollo, pues, éste se transformó en el destino común de la humanidad y en una obligación innegociable (Unceta, 2014).

Repasemos brevemente esta evolución. La idea del desarrollo como meta y como proceso se presentó como una gran teoría, que entró rápidamente en crisis y cuestionamientos. La metáfora del desarrollo, tomada de la vida natural, fue desvinculada totalmente de la realidad al conectarse con el crecimiento económico, que se transformó casi en su sinónimo. En la actualidad, aunque es ampliamente aceptado que el crecimiento no es analogía del desarrollo, los gobiernos despliegan discursos plagados de la palabra crecimiento. Se asumió como indiscutible la necesidad de enfrentar el reto del desarrollo como una sumatoria de datos nacionales agregados; si el país crece y prospera, entonces los individuos experimentarán mejoras en su bienestar.

Así, si el crecimiento económico se asumió como el modus vivendi de alcanzar el desarrollo; su herramienta fue "el equilibrio macroeconómico". De esta forma, la búsqueda desesperada por lograr los equilibrios, como parte de las políticas del Consenso de Washington, se ha mantenido hasta nuestros días.

En palabras de Unceta (2015), la economía del desarrollo no es otra cosa que una construcción intelectual destinada a justificar y promover la expansión y perpetuación de un modelo y de sus valores (los occidentales), utilizando esto como revulsivo para superar el supuesto atraso de sociedades diferenciadas por otras referencias culturales, organización social o su cosmovisión de la relación con la naturaleza.

En la implementación de la carrera hacia el desarrollo, a finales de los años sesenta e inicios de los setenta, comenzaron a surgir problemas y controversias en el modelo planteado de alcanzar el desarrollo mediante el crecimiento y la producción de bienes y servicios.

El primero de ellos fue el relativo a la pobreza y la desigualdad, pues resultaba inverosímil creer que aun poniéndose en marcha las políticas implementadas para incrementar el PIB, fenómenos como la pobreza, la desigualdad, las zonas periféricas o el subempleo continuarán aumentando. Estos resultados, en términos de desarrollo pusieron en tela de juicio la premisa que defendía que los incrementos porcentuales

1 Y profundizadas después del discurso de su toma de propuesta realizado por Harry Truman en 1949, donde incitaba a los países a salir del subdesarrollo, creando una dicotomía entre los países del norte o desarrollados, y los del sur o subdesarrollados. 
en la tasa de crecimiento de un país repercutían directamente en el bienestar social de la población. Si el objetivo de las políticas era cerrar las brechas norte-sur a través del crecimiento, entonces el fracaso era rotundo (Morawetz, 1977).

El segundo de los problemas fue el incipiente pero progresivo deterioro del medioambiente y de los recursos naturales, ( de hecho algunos científicos habían hecho sonar las alarmas, como Meadows (1972), pero fueron ignorados) a corto plazo comenzaban a manifestarse los problemas en nuevas enfermedades, problemas respiratorios, contaminación de capitales, mala calidad de agua, pero a largo plazo los problemas eran mayores: agotamiento de los recursos, pérdida de biodiversidad, alteraciones en el clima situaciones que ponían en riesgo la vida misma del ser humano.

El último de los problemas fue la no correspondencia entre crecimiento económico por un lado, y el respeto de las libertades y los derechos laborales e incluso humanos en gran parte del mundo, por el otro. La obsesión de la producción y aumento de crecimiento se lograron, pero a costa de ignorar los derechos humanos; esto en países dictatoriales o en otros donde se ponía en práctica el socialismo real.

En definitiva, el modelo de desarrollo no solo había fracasado; también había contribuido a expandir las asimetrías entre países "desarrollados" y "subdesarrollados", y el balance de poder había inclinado más la balanza hacia los países centrales (Unceta, 2015).

\section{De-construyendo el concepto de desarrollo}

\subsection{Del capital a los orígenes de la búsqueda del desarrollo}

Sabbatella y Tagliavini (2011) sostienen que ante las monomanías en el ambientalismo, los análisis de los vínculos entre el mundo social y el mundo natural se encontraban entre los valiosos aportes de la corriente teórica marxista y hegeliana. La distinción analítica propuesta no debe concebirse como dos definiciones cerradas e independientes, sino más bien como dos temas correlacionados entre sí. En ese sentido, en El Capital, Marx (2007) señala que la naturaleza y el trabajo son el punto de partida de la producción de valores de uso. Precisamente es en este trabajo donde el hombre se apoya constantemente por las fuerzas naturales. Bajo este marco, Marx (2000) arguye que el trabajo no se constituye como la fuente única y exclusiva de los valores de uso de la riqueza material que produce, sino que, como lo ha dicho William Petty, "el trabajo es el padre de la riqueza, y la tierra, su madre".

Tomando como referencia lo señalado anteriormente y alejándolo de su contexto histórico, el trabajo a lo largo de todos los tiempos ha fungido en la sociedad como el proceso de reciprocidad con la naturaleza, en donde el hombre se aprovecha de 
su ambiente y lo convierte para poder satisfacer sus propias necesidades básicas. Dicho de esta forma, no solo es fundamental el trabajo del hombre, sino que también el objeto y los medios de producción son necesarios para realizar el trabajo, donde éstos son obtenidos por la naturaleza. Dentro del proceso productivo las circunstancias materiales no frecuentan empatía, sin embargo Marx (2007) indica que sin éstas no se podría ejecutar exitosamente el ciclo productivo.

Bajo las condiciones descritas, la productividad dependerá del trabajo y de la producción de plusvalía. Al respecto, Sabbatella (2008) menciona que si prescindimos de la forma más o menos progresiva que presenta la producción social, veremos que la productividad del trabajo depende de toda una serie de condiciones naturales, las cuales se refieren a la naturaleza misma del hombre y a la naturaleza circundante. Del mismo modo, Marx (2007) sostiene que las condiciones de la naturaleza exterior se agrupan económicamente en dos grandes categorías: riqueza natural de medios de vida, o sea, fecundidad del suelo, riqueza pesquera, etc., y riqueza natural de medios de trabajo, saltos de agua, ríos navegables, madera, metales, carbón, etc.

Es prácticamente imposible poder entender y analizar el desarrollo sin antes poder vislumbrar bajo qué contexto se enmarca dicha noción. Por ello, debemos conocer bajo qué circunstancias histórico-sociales surge el concepto. Si bien es cierto que la civilización capitalista busca ganancias sin fin explotando al ser humano, imponiendo el consumismo, y promoviendo la producción y crecimiento cuantitativo sin fin, pero buscando la reducción de costos y generando expansión material que depreda bruscamente a la naturaleza, el sistema posee la probabilidad de generar crisis recurrentes, cuya salida es solamente trasladando dichas crisis a lo largo y ancho de la geografía mundial; dicho modo de producción está enfocado en garantizar la reproducción continua del capital y sus ganancias, gestando una crisis civilizatoria.

Más allá de la expansión material, el sistema capitalista necesita expandirse ideológica y culturalmente, con el fin de legitimar sus ganancias, la acumulación y la concentración de poder. En efecto, en dichos discursos es donde el capitalismo ha cimentado primero la idea de "progreso" y su consecuencia dominadora, el "desarrollo", con todas sus propuestas de correcciones instrumentales pero siempre enmarcadas en el modelo capitalista. Antes de profundizar en el tema, debemos considerar que en el mundo no existe una sociedad capitalista única, la cual refleje perfectamente las características y contradicciones del capitalismo, sino que coexisten varias sociedades capitalistas que interactúan en una especie de sistema-mundo, expandiendo y profundizando la lógica del capital (Wallerstein, 1996).

Por tanto, después de una reconfiguración del modelo capitalista superado el conflicto de la Segunda Guerra Mundial, en sus labores, surge por vez primera el concepto 
de desarrollo, convertido en la piedra angular de un discurso hegemónico desde el cual se ha tratado de controlar y ordenar los pueblos y sociedades del Tercer Mundo. Escobar (1996) afirma que el "desarrollo" es una versión del encuentro colonial, del dominio de occidente sobre el resto del mundo, que actúa de la misma forma que el colonialismo. Este se perpetua en sus discursos, como lo explicó Freire (2005) en La pedagogía del oprimido, entre oprimido-opresor, o bien Fanon (2012) en Los condenados de la tierra, con la dicotomía colonizado-colonizador. El concepto surge en el marco de un momento histórico de grandes cambios como fue la consolidación de los Estados-Nación, en el cual la justicia social lucha por su ausencia, debido a la situación geopolítica mundial de la de colonización en África, el inicio del mundo bipolar -como fue el caso de la URSS y EE.UU. -, la búsqueda de nuevos mercados, la confianza en la ciencia y la tecnología, y el crecimiento de áreas subdesarrolladas.

Así pues, la noción de desarrollo se concibe como el resultado de un proceso y construcción histórico y social, y por tanto es un concepto polisémico y polémico. Dicha idea está ligada a la idea del "progreso", con el propósito de mejorar y aumentar las condiciones de vida de las diferentes poblaciones, tomando como referencia a occidente e intentando acercarse a su modus vivendi. Se destaca en él un fuerte componente evolucionista-etapista eurocéntrico, de tal modo que subyace la idea de que los países occidentales han alcanzado un nivel superior al de los demás y deben ser, por ende, el modelo a seguir.

El término "desarrollo", como herramienta del capitalismo para alcanzar sus fines, ha ido modificándose y resignificándose a lo largo del tiempo, pero siempre ha mantenido su connotación positiva, aunque en la praxis no sea de este modo. De igual forma, el capitalismo desde sus inicios ha adoptado diferentes mutaciones, pero nunca olvidando su naturaleza depredadora expansionista. Dentro de esta metamorfosis podemos analizar esa capacidad integradora-desintegradora, aquella capacidad de expulsar y promover una falsa integración-armoniosa.

De lo anteriormente expuesto, podemos decir que el capitalismo posee dos modalidades bajo las cuales opera. Por una parte está una "fuerza centrípeta", cuyo fin es integrar y promover la atracción de países hacia su centro, corporaciones para incrementar su vorágine, de tal modo bajo un discurso en el cual enarbola las virtudes de los tratados de libre comercio e intensificación de mercancías, es capaz de atraer nuevos mercados -esto siempre en relaciones asimétricas-, y por otra parte, se encuentra otra fuerza que podríamos denominar "fuerza centrífuga", que es aquella que se expulsa y que habiendo usufructuado los países, corporaciones y sujetos, el mismo capitalismo se encarga de excluirlos. 
Desde el siglo XVIII con los mercantilistas y los fisiócratas se ha mantenido la base de que la modernidad y la riqueza provienen de la tierra, de la extracción y del intercambio de mercancías, y que estas actividades son beneficiosas e integran a la sociedad y al hombre. Sin embargo, el extractivismo ha provocado destrucción de la biosfera y resurgimiento de pobreza extrema, y el intercambio de mercancías ha provocado mayor desigualdad social. Además, en lugar de integración hemos presenciado expulsiones que podemos visualizar en el desempleo juvenil en Europa, las migraciones laborales y de refugiados, el aumento de la pobreza y la desigualdad como resultado de la concentración de poder y riqueza. A título ilustrativo, podemos notar como el $1 \%$ más rico incrementó sus ganancias en un $60 \%$ en 2012 , lo que se traduciría en poseer el monto suficiente para erradicar la pobreza del mundo 4 veces. Por otra parte, los bancos aumentaron sus activos un $160 \%$ en 2002, y en 2011 pasaron de 40 a 105 billones, es decir, más de 1,5 el PIB mundial. Empero, en 2010, aún en plena crisis, los beneficios de 5,8 millones de empresas en EUA aumentaron un 53\% y los impuestos que pagaron se redujeron en un $2.6 \%$, esto habla del poder del capitalismo de atraer y expulsar a su conveniencia a los diferentes actores (OXFAM, 2014).

Es relevante destacar la importancia del análisis del discurso del "desarrollo", puesto que es fundamental en la manera como representan y controlan el mundo quienes tienen más poder, es decir los capitalistas, y bajo el lenguaje capitalista todo proyecto está condenado a excluir a la inmensa mayoría y atraer-integrar, así mismo de manera asimétrica y temporal a unos pocos actores.

Este cruce entre la obsesión del desarrollo y la imagen de la naturaleza desmesurada, están en la base de muchos de los discursos y prácticas de nuestros gobernantes. Sin embargo, es difícil salirse del pensamiento impuesto, es decir no utilizando conceptos o constructos devenidos del norte capitalista.

\subsection{Desde una concepción materialista de la naturaleza}

Foster (2004), en su obra La ecología de Marx. Materialismo y naturaleza, reconstruye un concepto materialista-dialéctico de la naturaleza del marxismo para entender los orígenes de la ecología. Para ello, nos remonta a los aportes que han sido abandonados de tres grandes doctos, entre quienes se encuentran el filósofo griego Epicuro de Samos, el químico alemán Jostus Vib Liebig, y, finalmente, el naturalista inglés Charles Darwin. Según Sabbatella y Tagliavini (2011) Epicuro inspiró una perspectiva materialista de la naturaleza; Liebig desarrolló un enfoque desde el desarrollo sostenible, y Darwin adoptó una visión co-evolucionista de las relaciones entre la naturaleza y los seres humanos. Por tanto, ésta reconstrucción cambia completamente la producción intelectual marxista como impropia de la naturaleza. 
En la obra Manuscritos económicos-filosóficos de 1844, Marx (2004) concibe a la naturaleza como: "el cuerpo inorgánico del hombre" (p. 112). En ese sentido, el pensamiento marxista defiende que el hombre vive de la naturaleza, esto quiere decir que la naturaleza es su cuerpo, con el que debe permanecer en un proceso continuo, a fin de no perecer. El hecho de que la vida física y espiritual del hombre dependa de la naturaleza no significa otra cosa sino que la naturaleza se relaciona consigo misma, ya que el hombre es una parte de la naturaleza.

Vedda (2004) señala que para Marx no existe dicotomía entre el ser humano y la naturaleza. Esta no es algo externo o un mundo exterior, y ante ello expresa: "El hombre no está en la naturaleza, sino que es naturaleza". La naturaleza le ofrece al hombre su medio de vida inmediato, así como la materia, el objeto y la herramienta de su actividad vital, es decir el trabajo (Sabbatella \& Tagliavini, 2011).

\subsection{Desde la relación trabajo-naturaleza en la producción de valores de uso}

Marx (2014) sostiene que la relación entre el trabajo y la naturaleza constituyen la piedra angular de la producción de valores de uso, para lo cual el ser humano se apoya en las fuerzas naturales. El pensamiento marxista nos dice también que el trabajo no es el único ni exclusivo punto de partida para la producción de estos valores de la riqueza natural. En palabras de Marx (2000): "el trabajo no es, pues, la fuente única y exclusiva de los valores de uso que produce, de la riqueza material. El trabajo es, como ha dicho William Petty, el padre de la riqueza, y la tierra la madre" (p. 10).

Dejando de lado la línea del tiempo, el trabajo ha sido desde siempre el elemento consustancial de intercambio entre la naturaleza y la sociedad, ya que permite la obtención de los recursos para la satisfacción de sus necesidades básicas. Según Sabbatella y Tagliavini (2011) durante el proceso de trabajo interviene no sólo el trabajo del hombre, sino también el objeto sobre el cual se realiza y los medios de trabajo, ambos brindados por la naturaleza. Además, el marxismo destaca las condiciones materiales que no suelen identificarse dentro del proceso productivo, puesto que al fungir como la espina dorsal del proceso, de ésas depende la productividad del trabajo y la generación de plusvalía. Marx (2000) nos invita a desprendernos de la idea errónea de la producción social, para ello nos demuestra cómo la productividad del trabajo se desprende de todo un conjunto de condiciones naturales, las mismas que relacionan a la naturaleza del hombre y la naturaleza adyacente. Las condiciones naturales mencionadas anteriormente, según Marx (2008) se agrupan económicamente en dos grandes categorías: riqueza natural de medios de vida, o sea, fecundidad del suelo, riqueza pesquera, etc., y riqueza 
natural de medios de trabajo, saltos de agua, ríos navegables, madera, metales, carbón, etc.”.

Por otra parte, para entender qué es desarrollo es también necesario analizar bajo que contexto se enmarca la noción del desarrollo. Es por ello, que debemos conocer bajo qué circunstancias histórico-sociales surge el concepto.

Como sabemos, el sistema capitalista busca la acumulación incesante de capital, y esto solo puede ser logrado mediante la explotación del hombre por el hombre, o del hombre hacia la naturaleza. Sin embargo; el objetivo de aumentar las ganancias ad finitum, el sistema capitalista incurre en numerosas contradicciones ${ }^{2}$ cuya repercusión en nuestra sociedad son las más frecuentes y profundas crisis económicas. Como lo menciona Harvey, el sistema capitalista carece de la facultad de resolver las crisis de manera definitiva, y lo que logra, es trasladar las crisis a lo largo y ancho del planeta, modificándolas en su matriz, es decir: de crisis de subproducción, a crisis financieras o crisis de sobreproducción, entre otras. (Harvey, 2014)

De tal modo, para profundizar y perpetuar el sistema capitalista, ha enarbolado un discurso ideológico entorno a la imperiosa necesidad de concebir el crecimiento como una Teleología. Tal urdimbre ideológica ha partido en dos frentes; el primero de ellos realizado bajo el discurso de la libertad y la democracia como elementos naturales del capitalismo e inherentes al ser humano. ${ }^{3}$ En el cual el hombre ha dejado de ser un ciudadano (Homo politicus) y ha pasado a ser parte de un (Homo economicus) el cual ejerce su capital social con plena libertad de elección ofertando su mano de obra al mejor postor. El otro frente ha partido desde las instituciones creadas después de la Segunda Guerra Mundial (FMI, BM, BID entre otras) en el cual la meta alcanzar es el progreso, y su consecuencia dominadora el desarrollo. (Quijano, 2000) Finalmente, antes de concebir que existen alternativas al modelo imperante, (u otros mundos en palabras del EZLN), debemos entender que el sistema capitalista, no es único y homogenizado, no existe un sistema capitalista puro y ejemplar, si no hibridaciones del mismo, con diferentes rostros y matices, pero todos ellos con la misma matriz: la acumulación incensante de capital.

\footnotetext{
2 Para una mejor comprensión de las contradicciones del capitalismo, revisar a: Harvey, D. (17). Contradicciones y el fin del capitalismo. Foladori, G., \& Melazzi, G. (1987). Economía de la sociedad capitalista (vol. 126). Ediciones de la Banda Oriental.

3 Para un profundo análisis acerca de la restructuración de la democracia, mediante el neoliberalismo revisar: McRobbie, A. (2016). The end of the social and the denigration of democracy: Wendy Brown, Michel Foucault and Neoliberalism: a review essay. Soundings: A journal of politics and culture, 61(1), 117-123.
} 


\section{La utopía del doradista}

Tomás Moro en una de sus obras más populares hace referencia al surgimiento de un Estado ideal en forma de república, todo esto enmarcado en una serie de asuntos de carácter económico, filosófico y político, donde la propiedad común de los bienes y la convivencia pacífica de sus miembros viene a ser el estilo de vida de la comunidad que habita en la isla Utopía. Dos siglos más tarde, Jean-Jacques Rousseau publica un escrito denominado Los principios del derecho político o más conocido como El Contrato Social, un gran texto filósofo-político que promulga la libertad e igualdad de los individuos bajo un Estado que es instituido por la voluntad social, es decir, por el "contrato social".

Frente a la existencia de un modo de producción capitalista depredador de la vida misma, en nuestros días llama la atención que desde el siglo XV dos grandes pensadores hayan desarrollado ideales que permanecen presentes y hayan permitido a otros tomarlos como base para la propuesta de vías alternativas, en diferentes campos tal como el económico. Al hacer referencia a este enfoque, nos introducimos a hablar sobre el rumbo que pueden tomar aquellas economías que ansían alcanzar un desarrollo endógeno que garantice el pleno bienestar social de sus habitantes, presentadas como una nueva doctrina de desarrollo.

Habiendo realizado un breviario del surgimiento del término "utopía", nos remontaremos también hacia los orígenes de la terminología del "doradista” ya que está vinculado con la perspectiva actual del desarrollo-extractivista. Es preciso citar a Rene Zavaleta, pensador boliviano que en los años sesenta ya hacía referencia en su vocabulario al término «doradista», el cual usaba para catalogar a los latinoamericanos como individuos que llevan en su corazón el dogma del “doradista”, el mismo que tiene que ver con el hecho de que cuando se descubre un nuevo recurso natural (que es considerado estratégico en función del ciclo económico), rápidamente, se crea la precepción de que el país podrá alcanzar el sendero del desarrollo y acortar las brechas del norte y del sur, para alcanzar de esta forma el anhelado Estado mágico utópico-doradista. (Zavaleta, 1967).

En ese sentido, esta visión utópica-doradista recorre toda América Latina, y en el fondo habla de la abundancia, tanto de sus ventajas como de sus desventajas. El ecuatoriano Alberto Acosta también ha desarrollado más a fondo esta temática, al punto que utiliza esta paradoja para hablar de la paradoja que se da cuando una región pobre es a su vez rica en recuersos naturales, afirmando quepor la insuficiente capacidad de aprovechar al máximo estos beneficios, las regiones menos favorecidas siguen estancadas (Acosta, 2009). Este estancamiento se genera por la tendencia a la monoproducción, que tergiversa nuestras propias estructuras económicas, 
mediante la instalación de nuevos nichos de desigualdad y de reprimarización de las economías más débiles. Pratt (2009), retoma precisamente este tema en su libro Ojos imperiales, y señala que Humboldt y sus recorridos por América Latina en el siglo XIX, dieron lugar a un discurso de la América Latina poseedora de abundancia, inocencia y acumulación infinita de los recursos naturales, y es así donde nace la locución: "un mendigo sentado sobre un saco de oro".

No obstante, toda iniciativa de desarrollo que se encuentre anclada en la visión del "doradista" de Zavaleta, es "un modelo de desarrollo que depreda la naturaleza", y por tal razón, no puede ser concebido como una propuesta de cambio estructural-innovador, puesto que al final, lo que se está efectuando es un trueque de la riqueza de los recursos naturales por recursos monetarios, donde dicho proceso estará sujeto a los intereses del Gobierno en turno. Bajo este marco, aduciendo y reconociendo los postulados de Zavaleta y Acosta, coincidimos con Galeano cuando afirma que la utopía está en el horizonte, y en el intento de las economías en vías de desarrollo al caminar por el sendero "dorado" de los recursos naturales, al final la utopía permite a las economías emergentes caminar, eso sí sin dejar de lado las discrepancias de tinte político que puedan aparecer durante el recorrido.

\section{Un modelo de desarrollo que depreda la naturaleza y oprime la justicia social}

Para continuar con su naturaleza de acumulación y expansión, el capitalismo ha utilizado en su praxis la idea del progreso y desarrollo, como una estrategia de hegemonía imperante. América Latina ha sido una de las regiones que ha experimentado de cerca el pasar del Consenso de Washington, ${ }^{4}$ asentado sobre la valorización financiera al consenso de los commodities, que está basado precisamente en la extracción y exportación de bienes primarios a gran escala desde los países de la periferia hacia los países del centro.

A partir de ese episodio, durante los últimos treinta años y con mayor fuerza los últimos diez años, el consenso de commodities ha llevado a las economías a una nueva división internacional del trabajo, la cual condena a América Latina a un evento histórico de su época post-colonial que es la exportación de naturaleza. Ante ello, los ciclos económicos devenidos del norte nos han venido minimizando y desdibujando

4 Recordemos de forma resumida que el Consenso de Washinģton fue el paquete de reformas "estándar" para los países en desarrollo azotados por la crisis, según las instituciones bajo la órbita de Washinģton, D.C. como el Fondo Monetario Internacional, el Banco Mundial y el Departamento del Tesoro de los Estados Unidos. Las fórmulas abarcaban políticas en áreas tales como la estabilización macroeconómica, la liberación económica con respecto tanto al comercio como a la inversión y la expansión de las fuerzas del mercado dentro de la economía doméstica. 
las consecuencias ambientales y sociales, políticas y culturales que tienen la implementación de estos modelos.

Por tanto, hablamos del consenso de los commodities porque está asentado en el hecho de que el boom del precio de las materias primas, (petróleo, minería y otras actividades) está inmiscuido en un orden socioeconómico que implica una percepción productivista del desarrollo, es decir, una aceptación de América Latina como una región exportadora de naturaleza. En ese sentido, el consenso de commodities se presenta como un discurso único que se instala en un ámbito lleno de tensiones y ambivalencias, en la cual coexisten discursos y prácticas desde la ideología neoliberal, conocida también como "neodesarrollismo progresista" o llámese control estatal de la renta extractivista.

Partiendo de las premisas anteriores, se han implementado fuertes modelos de despojo y acumulación por desposesión. Así lo que tenemos en última instancia es un modelo de ocupación territorial; en ese sentido, los modelos destruyen la economía precedente y la reorientan para adaptarla a la consolidación de ese modelo. En la mayoría de los casos, estos proceden sin el aval de las poblaciones y buscan controlar no solo la producción, sino la reproducción de la vida de esos territorios.

En cuanto al neoextractivismo, este hace alusión a la sobreexplotación de los recursos naturales cada vez más escasos o agotables, o a la expansión de la explotación hacia territorios considerados antes como improductivos. Este proceso no solo se reduce al petróleo o a la minería, sino que abarca la expansión del territorio a deforestar y actividades tales como los agronegocios o agrocombustibles, que se quieren implementar a lo largo y ancho del territorio latinoamericano. Una característica de lo que denominamos neoextractivismo son los proyectos a gran escala, los cuales son distintos al estandarte común. En virtud, no hablamos de pequeños emprendimientos, sino de mega proyectos, los cuales impactan fuertemente en la economía y en el medioambiente, ya que estos utilizan grandes cantidades de agua y energía, e intervienen directamente en grandes extensiones de territorio.

Volviendo una mirada a los postulados de la Comisión Económica para América Latina y el Caribe, en lo que respecta a la reprimarizacion de las economías latinoamericanas, reconocemos que la exportación de materias primas es cada vez mayor. Ahora bien, con la incorporación del nuevo gigante asiático, China, su anexión tiene un efecto mayor e inmediato en nuestras economías. Esto se debe a que China interviene exigiendo un intercambio asimétrico de materias elaboradas y tecnológicas a cambio de materias primas. No es de sorprenderse que para 1990 la participación china dentro del comercio exterior representaba el 0,06\% y diecinueve años más tarde, éste representando el 10\% (CEPAL, 2011). 
Este efecto de reprivatización tiene que ver con la tendencia del monocultivo o la monoproducción que atraviesa a todos los países latinoamericanos esto crea que las economías de enclave o enclaves de exportación efectivamente creen territorios socio-económico dependientes del mercado internacional, cerrando toda posibilidad de generar encadenamientos endógenos al interior de sus sociedades, tanto a nivel local, como regional. La última característica del neoextractivismo es la conflictividad,pues ha habido un boom de conflictos socioambientales en los últimos 10 años, debido a que bajo este modelo van configurando u ocupando territorios que afectan enormemente a las poblaciones que radican en ellos.

En ese plano, nos gustaría insistir en los imaginarios o idearios que recorren por América Latina acerca de la naturaleza del desarrollo, siendo este no solo parte del discurso político, sino también del pensamiento, el mismo que está recorrido por una obsesión de la búsqueda del desarrollo que se ha hecho explícita en los discursos industrialistas a partir de los años cuarenta o cincuenta. Todo esto de la mano de los procesos de industrialización sustitutiva de importaciones. Ya en los años cincuenta-sesenta la condición era más crítica y existían duros cuestionamientos acerca de la especialización de la economía en la exportación de materias primas y hacia énfasis en un discurso industrialista. Sin embargo, en ese pensamiento que intentó buscar las vías del desarrollo autónomo económico en América Latina, no había cuestionamientos sobre el medioambiente, que es algo que a partir de los años setenta comienza a recorrer con mayor espesor a partir de las resistencias, así como también de la mano con un discurso social cimentado en la necesidad de combatir el aumento de las brechas sociales entre sur y norte, en contradicción del discurso imperante.

Es allí donde comienzan a vislumbrarse más allá del discurso desarrollista imperante, la existencia de las grandes desigualdades sociales, pero sin duda desde el paradigma ambiental, es desde donde comienza a erosionarse de una manera mayor esa capacidad omnicomprensiva del desarrollo. Los ecologistas entrecruzan este paradigma con otras voces como lo son algunos movimientos indigenistas, donde también critican la idea del desarrollo hegemónico basado en productividad y crecimiento como fin en sí mismo.

Es en ese tiempo surge el concepto de desarrollo sustentable, que ya tenía algunas décadas de existencia y capacidad de interpelación disruptiva, y fue apropiado por las grandes corporaciones que hoy lo utilizan para legitimar sus proyectos extractivos. En ese marco, queremos incluir o hacer una breve mención a la crítica post-estructuralista que tiene a Escobar (1996) como uno de sus representantes, quién intentó desmontar lo que es en discurso y en términos de poder indagar qué 
es lo que hay detrás de esta noción productivista-extractivista de desarrollo -que poco tiene en cuenta las voces de las poblaciones y el medio ambiente-.

Si bien, esta noción ha sido muy crítica, ya que se han visto sus limitaciones ambientales y geográficas, lo desmotivante es que retorna y apropia conceptos más o menos disruptivos y se constituye en una suerte de relato homogeneizador, el mismo que ahora no viene de la mano de un discurso del progreso o industrialista, sino más bien de una práctica claramente extractivista.

Dicha práctica ha sido solapada, promovida y aceptada por gobiernos incluso de corte progresista, aduciendo en gran parte al papel histórico que le han dado la división internacional del trabajo le ha asignado a América Latina, que es de proveedora de materias primas. Mientras que ahora lo hacen en nombre del discurso de ventajas comparativas, en definitiva lo que están señalando es que las economías son adaptativas a los ciclos económicos que impone precisamente la división internacional del trabajo.

En síntesis, cuando hablamos de "imaginarios del desarrollo" creemos que es pertinente hacer énfasis en la necesidad de recorrer la naturaleza del pensamiento y de la política latinoamericana, porque en realidad no solo tenemos la visión eurocéntrica que implica o ve la naturaleza como una mera cuestión instrumental, o como una mera canasta de recursos. En todo caso, en América Latina hay un plus, un plus que tiene que ver con la idea de que la región es por excelencia el lugar de los recursos naturales, que recorre el imaginario político al literario y podríamos decir que lo retroalimenta y se puede ver sintetizado el científico alemán Humbolt.

\section{Conclusiones: Una propuesta desde el sur, el Sumak Kawsay- desarrollo con justicia social.}

De acuerdo con lo expuesto con anterioridad, los estudios del desarrollo se debaten entre tres opciones:

1. Esfuerzos orientados a ampliar el concepto pero sin alterar su naturaleza ni metodología. (Aumentar la producción, seguir con el consumismo, continuar con la desigualdad, la pobreza, el deterioro ambiental etc.)

2. La negación del desarrollo como noción universal, abandonando la empresa.

3. Intentos encaminados a la reorientación profunda del concepto y de las estrategias del desarrollo. (Esa propuesta no puede ser el resultado de un proyecto voluntarista; debemos considerar los limites reales, materiales, naturales de nuestro planeta, y las deficiencias u omisiones teóricas del concepto).

En palabras de Latouche (2008) podemos justificar el hecho de que algunos teóricos buscan crear conel Sumak Kawsay un sincretismo de ideas con el decrecimiento 
$\mathrm{y}$ viceversa. El decrecimiento, como tal, no es verdaderamente una alternativa concreta; sería, más bien, la matriz que daría lugar a la eclosión de múltiples alternativas donde Sumak Kawsay, el post-capitalismo y el decrecimiento -por mencionar sólo algunos- podrían convivir y retroalimentarse dónde el fin último sería vivir sin carestías y en armonía con la naturaleza. Evidentemente, cualquier propuesta concreta o contrapropuesta es necesaria y problemática bajo el actual modelo de desarrollo.

El Sumak Kawsay, se presenta como una traducción o interpretación de la cosmovisión andina, pero también como una alternativa al desarrollo (aún difusa y en constante construcción), situándose más allá de la ecuación: producción-mercado-consumo-bienestar. Sea cual fuese el enfoque tomado, el Sumak Kawsay coincide en cumplir una serie de requisitos para su consecución, entre los que destacaremos cuatro, que son a grosso modo: romper con la concepción judeocristiana del dualismo sociedad-naturaleza, la austeridad frente al derroche, la defensa de las identidades culturales (respeto y defensa de la heterogeneidad cultural) y el último y más citado: la autonomía de los procesos de cada territorio. Con ello, el Sumak Kawsay, intenta romper con la homogenización cultural y busca ser una propuesta introducida desde abajo, de forma horizontal, descentralizada y consensuada por los diferentes actores que se ven involucrados, donde prime crear las condiciones necesarias para que el hombre viva en bienestar a través de relación armoniosa con la naturaleza, y en la recuperación $y$ perpetuación de prácticas y saberes tradicionales que el modelo actual de producción ha orillado y tildado de "bárbaro o atrasado". Bajo esta perspectiva, la autonomía de los pueblos y regiones fungiría como eje vertebral de cualquier estrategia del Sumak Kawsay (Unceta, 2015).

La superación de la civilización signada por el capital implica cambiar la raíz de su vertiente existencial: su modo de producción y reproducción de la vida social y de interrelación con la naturaleza. De acuerdo con Rauber (2015) no habrá nueva civilización, ni liberación, ni vida posible, si los cambios se limitan a sustituir a los patrones de los centros del poder de mando del capital, pero dejan intactos sus mecanismos de funcionamiento, que son los de su producción y reproducción.

Lo expuesto anteriormente nos obliga a repensar un modelo de producción económico social alejado de toda órbita del sistema capitalista. Este proceso de transformación constituye uno de los grandes retos dentro del terreno político, cultural, económico, social e ideológico de un mecanismo de sustitución y superación del orden económico, que usufructúa la propiedad privada gracias a su elemental herramienta de producción: el capital.

En este contexto, una primera conclusión es que ni la reforma ni la reparación del capitalismo son posturas suficientes y profundas que conlleven un cambio 
sustancial, de hecho, en algunos casos pueden ser necesarias para atender urgencias y problemas muy puntuales pero no de largo alcance, ni esbozan una idea de cambiar la relación del hombre con la naturaleza y su apropiación y explotación de recursos, ni menos atienden a la problemática de la externalización y socialización de los impactos ambientales.

Es necesaria una transformación profunda que aborde la base ideológica del capitalismo y del desarrollo, que el cambio no debe ser sólo económico, sino cultural y político. Podríamos esgrimir la idea de que una opción que priorice el valor del uso sobre el valor de cambio es un gran primer paso. Sin embargo esta idea aún sigue atrapada en este antropocentrismo, donde la tarea a seguir es romper con esa dualidad natura-hombre.

Así, las estrategias a seguir deberían enfocarse no en una salida al subdesarrollo, sino en una salida del capitalismo, y así dejar en claro que el desarrollo bajo el imperante sistema productivo es inviable, y como dispositivo de poder debe ser descalificado en la medida que representa una continuación de las lógicas coloniales, enmarcadas culturalmente en la dicotomía eurocéntrica salvaje-civilizado.

Entre las alternativas al capitalismo emergen con fuerza la recuperación de cosmovisiones andinas o de corte comunitario, llámese buen vivir, Sumak Kawsay, en los andes, Ubuntu en Sudáfrica o el uMunthu en Malawi o svadeshi, sarvodaya o el swaraj y Aparigrah en la India, el Gadugi de los cherokees, el Meitheal en Irlanda, el Talkoot en Finlandia, el Naffir en Sudan, el Bayanihan en Filipinas, Gotong-royong en Malasia y un gran número de diferentes proyectos alternativos en otras latitudes, en donde se proponen como base la autosuficiencia y la autogestión de personas viviendo en comunidad, entendiendo que los seres humanos somos naturaleza y deberíamos convivir con ella en armonía. Pero esto implica profundas transformaciones sociales, culturales, económicas, políticas etc. Donde prime una economía basada en la reciprocidad y no en las ganancias de solidaridad y no de competencia, de sustentabilidad y no de crecimiento, de suficiencia y no de acumulación, de inclusión social y no de individualismo, de relacionalidad y no de explotación de la naturaleza.

Rauber (2015) afirma que hoy en día está claro y se reconoce que la biósfera no solo es fuente generadora de vida y de recursos energéticos, sino también reguladora del equilibrio global del sistema, el mismo que guarda concordancia con lo que las civilizaciones precolombinas (andinas) denominan desde hace muchos siglos como la "Pachamama" o como "Madre tierra". Desde esta óptica, la naturaleza funge principalmente como la columna vertebral del equilibrio general para conservar el patrimonio de la biodiversidad para las siguientes generaciones; ante 
esta perspectiva, la naturaleza ya no solo es vista como una fuente de recursos y materias primas.

En esta dimensión ecológica de la realidad, los seres humanos nos reconocemos como parte intrínseca e indivisible de la naturaleza. Tal es la perspectiva cosmo-céntrica que posibilita pensar en el futuro humano con un sentido y concepción diferentes del progreso y bienestar. Esto se resume en el Sumak Kawsay, raizalmente defensor-promotor de la vida humana en armonía con la naturaleza. En tal sentido, resulta claro que las cuestiones ecológicas o referidas a la naturaleza no pueden ser analizadas de modo aislado, como tampoco lo puede ser lo relativo a la pobreza, el desarrollo, la democracia, etc. Es indispensable el enfoque integral sistémico (economía, política, cultura, modo de vida) de la vida en las realidades sociales en cada momento.

Deben centrarse los esfuerzos en las "sustancias" (superación del capital) y no sólo en las "formas" (superación del subdesarrollo). Hay que pensar el mundo desde el Sumak Kawsay o el svadeshi, o apargrama, etc. Mediante el cual implica idear un mundo post-capitalista donde desaparezca la explotación del hombre por el hombre, exista una relación diferente con la naturaleza, se privilegie el valor del uso sobre el valor de cambio, se termine con la mercantilización y le fetichismo de todas las relaciones humanas y se termine con el deterioro de las condiciones de vida de la población para sostener el crecimiento y acumulación del capital, en definitiva, la supremacía del ser humano sobre el capital.

Es momento de desechar la concepción antropocéntrica para construir una cosmovisión biocéntrica al servicio de la vida misma, del bienestar mundial y del hombre promedio.

\section{Referencias}

Acosta, A. (2009). La maldición de la abundancia. Quito: Abya-Yala.

Berges, C. \& Sabbatella, I. (2008). Una aproximación a las desigualdades ambientales. En América Latina en movimiento. Recuperado de http://www.alainet. org/es/active/24939

Brown, W. (2015). Undoing the Demos: Neoliberalism's stealth revolution. Zone Books, MIT Press.

CEPAL. (2011). La República Popular China y América Latina y el Caribe: hacia una nueva fase en el vínculo económico y comercial. Santiago de Chile. Recuperado de http://repositorio.cepal.org/bitstream/handle/11362/2995/S2011010_ es.pdf;jsessionid=4321B0831318EE6480EADFC9C68F96D9? sequence $=1$ 
Escobar, A. (1996). La invención del Tercer Mundo, Construcción y deconstrucción del desarrollo. Caracas: Ministerio del Poder Popular para la Cultura.

Fanon, F. (2012). Los condenados de la tierra. Madrid: Fondo de Cultura Económica de España.

Foster, J. B. (2004). La ecología de Marx. Materialismo y naturaleza. España: El Viejo Topo. Recuperado de https://radiozapatistasud.files.wordpress.com/2011/11/ bellamy-foster-john-la-ecologc3ada-de-marx.pdf

Harvey, D. (2014). Seventeen Contradictions and the End of Capitalism. Oxford University Press. (UK).

Latouche, S. (2008). La apuesta por el decrecimiento: ¿Cómo salir del imaginario dominante? Barcelona: Icaria.

Marx, K. (2000). El Capital. Crítica de la economía política. México: Fondo de Cultura Económico (FCE).

Marx, K. (2004). Manuscritos Económico-filosóficos de 1844. (M. Vedda, Trad.) Buenos Aires: Ediciones Colihue.

Marx, K. (2007). El Capital. Madrid: Fondo de Cultura Económica (FCE).

Marx, K. (2014). El capital: Crítica de la economía política, tomo I, Libro I. El proceso de producción del capital (Cuarta ed.). México: Fondo de Cultura Económico (FCE).

Meadows, H. (1972). Los límites del crecimiento: informe al Club of Rome sobre el predicamento de la humanidad. México: Fondo de Cultura Económica.

Morawetz, D. (1977). 25 Years of Development 1950 To 1975. Nueva York: Jhon Hopkins Press.

Paulo, F. (1970). Pedagogía del oprimido. México: Siglo veintiuno editores, SA.

Pratt, M. (2009). Ojos imperiales: Literatura de viajes y transculturación. México D.F.: Fondo de Cultura Económico.

Quijano, A. (2000). Colonialidad del poder, eurocentrismo y América Latina. En Lander E. (Comp.). La colonialidad del saber: eurocentrismo y ciencias sociales. Perspectivas Latinoamericanas. Buenos Aires, Argentina: CLACSO, Consejo Latinoamericano de Ciencias Sociales. p. 246. Recuperado de http://bibliotecavirtual.clacso.org.ar/ar/libros/lander/quijano.rtf 
Rauber, I. (2015). El Buen Vivir: una concepción integral del desarrollo, la democracia, los derechos. Caracas. Recuperado de http://www.olacom.org/el-buen-vivir-una-concepcion-integral-del-desarrollo-la-democracia-los-derechos-isabel-rauber/

Rousseau, J. J. (1965). El contrato social, trad.

Sabbatella, I., \& Tagliavini, D. (2011). Marxismo Ecológico: Elementos fundamentales para la crítica de la economía-política-ecológica. Herramienta 47, 3-12.

Tomás, M. (2006). Utopía. Ediciones Colihue SRL. OXFAM. (2014). Informe OXFAM 2013. OXFAM.

Unceta, K. (2014). Desarrollo, postcrecimiento y Buen Vivir: Debates e interrogantes. Quito, Ecuador: Ediciones Abya-Yala. Recuperado de http://rosalux.org.ec/ attachments/article/830/Desarrollo,\%20postcrecimiento.pdf

Unceta, K. (2015). Más allá del crecimiento. Buenos Aires: MarDulce.

Vedda, M. (2004). Introducción. En Marx, K. (Ed.), Manuscritos Económico-filosóficos de 1844, (pp. VII - XLI). Ediciones Colihue SRL.

Wallerstein, I. (1996). Después del liberalismo. Madrid: UNAM-Siglo XXI editores.

Zavaleta, R. (1967). Bolivia: el desarrollo de la conciencia nacional. Montevideo: Diálogo. 